\title{
Pathological Diagnosis of Early Colorectal Carcinoma and Its Clinical Implications
}

\author{
Takahiro Fujimori $^{a}$ Shigehiko Fujii ${ }^{a}$ Natsuko Saito $^{a}$ Kenichi Sugihara ${ }^{b}$ \\ a Department of Pathology, Dokkyo Medical University, Tochigi, and b Department of Surgery, Graduate School of \\ the Tokyo Medical and Dental University, Tokyo, Japan
}

\section{Key Words}

Colorectal submucosal invasive carcinomas $\cdot$ Endoscopic

treatment $\cdot$ Budding/sprouting $\cdot$ Depth of invasion

\begin{abstract}
This review consists of 6 sections: (1) pathological diversity of cancer and the correlation between 'zokushutsu' (budding/sprouting) and lymph node metastasis; (2) genetic analysis and metastasis in the gastrointestinal tract; (3) conditions requiring resection after endoscopic treatment; (4) improvement of methods used to measure depth of submucosal invasion in the Ip type; (5) Japanese morphological classification of colorectal neoplastic lesions in terms of the clinical pathology and genetics of laterally spreading tumors; (6) villous tumors.

Copyright $\odot 2009$ S. Karger AG, Basel
\end{abstract}

\section{Introduction}

The Japanese Gastroenterological Association convened core symposia, entitled 'Problems at the Clinical and Pathological Point of Tangency: Pathological Diagnosis of Early Colorectal Carcinoma and Its Clinical Implications' at its 3rd annual meeting (February 2007 in
Tokyo, organized by Kenichi Sugihara, Department of Surgery, Tokyo Medical and Dental University, Tokyo) and at its 4th annual meeting (February 2008 in Osaka, organized by Tetsuo Arakawa, Department of Gastroenterology, Osaka City University, Osaka). This review summarizes these presentations and revises and extends our previous work in this field.

Core symposium 3 consisted of 12 participants. Kawamata et al. [1] spoke comprehensively of the diversity of cancer cells from the time of cancerization to the time of invasion or metastasis. Sugai et al. analyzed laterally spreading tumors (LSTs) [2] in a molecular pathological way and discussed their specific macroscopic findings and the genetic background. LSTs have received clinical attention in Japan because of the variety of macroscopic findings among such tumors and their specificity of growth and advancement [3]. In particular, heterogeneity between LSTs and common tumors that develop from adenomas, as well as the so-called villous tumors, have been discussed. The subject of 4 presentations by Matsuda et al., Tamura et al., Maruyama et al. and Yasuda et al. was parameters as risk factors for lymph node metastases in pathologically diagnosed invasive submucosal (SM) colorectal adenocarcinoma. Their results showed that it was important to conduct various clinicopathological analyses, including examination under magnification, in

\section{KARGER \\ Fax +41613061234 \\ E-Mail karger@karger.ch}

www.karger.com (c) 2009 S. Karger AG, Basel

0012-2823/09/0795-0040\$26.00/0

Accessible online at:

www.karger.com/dig
Takahiro Fujimori

Department of Pathology

Dokkyo Medical University

880, Kitakobayashi, Mibu, Shimotsuga, Tochigi (Japan)

Tel. +81 28287 2130, Fax +81 28286 1681, E-Mail t-fuji@dokkyomed.ac.jp 
Table 1. Multivariate analysis of risk factors for lymph node metastasis [4]

\begin{tabular}{|c|c|c|c|}
\hline Factors & $\begin{array}{l}\mathrm{p} \\
\text { value }\end{array}$ & $\begin{array}{l}\text { Odds } \\
\text { ratio }\end{array}$ & $95 \% \mathrm{CI}$ \\
\hline Sex (men/women) & NS & & \\
\hline Age ( $<60$ years/ $\geq 60$ years $)$ & NS & & \\
\hline Location $(\mathrm{R}, \mathrm{S}, \mathrm{D} / \mathrm{T}, \mathrm{A}, \mathrm{C})$ & NS & & \\
\hline $\begin{array}{l}\text { Status of muscularis mucosae } \\
\quad \text { (identifiable/not identifiable) }\end{array}$ & NS & & \\
\hline $\begin{array}{l}\text { Histological type at the deepest } \\
\text { portion (well, moderately/ } \\
\text { poorly differentiated) }\end{array}$ & NS & & \\
\hline SM depth $(<1,000 / \geq 1,000 \mu \mathrm{m})$ & 0.006 & 5.404 & $1.623-17.933$ \\
\hline $\begin{array}{l}\text { Lymphatic invasion } \\
\text { (negative/positive) }\end{array}$ & $<0.0001$ & 4.691 & $2.768-7.950$ \\
\hline $\begin{array}{l}\text { Venous invasion } \\
\text { (negative/positive) }\end{array}$ & $<\mathrm{NS}$ & & \\
\hline $\begin{array}{l}\text { Budding/sprouting } \\
\text { (negative/positive) }\end{array}$ & $<0.002$ & 2.276 & $1.350-3.835$ \\
\hline
\end{tabular}

NS = Not significant $\mathrm{R}=$ rectum; $\mathrm{S}=$ sigmoid colon; $\mathrm{D}=\mathrm{de}-$ scending colon; $\mathrm{T}=$ transverse colon; $\mathrm{A}=$ ascending colon; $\mathrm{C}=$ cecum.

order to limit risk factors (table 1) [4]. Kawachi et al. and Ueno et al. emphasized the importance of tumor budding or sprouting at the invasive front [5]. Kazama et al. presented similar results, but discussed the need for various special stainings for the assessment of budding or sprouting [6].

Kitajima et al. discussed the clinicopathological significance of measuring the level of invasion in early colorectal carcinoma - assuming that this level is predictive of lymph node metastasis - on the basis of the General Rules for Clinical and Pathological Studies of Cancer of the Colon, Rectum and Anus, as proposed by the Japanese Society for Cancer of the Colon and Rectum (table 2) [3]. Mashimo et al. particularly emphasized the specificity of Ip-type SM colorectal cancer. She concluded that because Ip-type cancer was more easily treated with endoscopy than non-Ip-type cancer and because it had lower rates of recurrence and metastasis, it was clinically important to differentiate both by endoscopy $[7,8]$.

Various presentations were given at this symposium, and some of the results differed among the presenters. Therefore, the chairpersons summarized the discussions at the symposium as follows. The chairpersons were Kenichi Sugihara (as stated before) and Takahiro Fujimori (Department of Pathology, Dokkyo Medical University, Tochigi).

Pathological Diagnosis of Early

Colorectal Carcinoma
Table 2. Relationship between the rate of lymph node metastasis and SM depth [4]

\begin{tabular}{lrllll}
\hline SM depth, $\mu \mathrm{m}$ & \multicolumn{2}{c}{ Ip type } & & \multicolumn{2}{c}{ Non-Ip type } \\
\cline { 2 - 3 } \cline { 6 - 7 } & $\mathrm{n}(-)$ & $\mathrm{n}(+)$ & & $\mathrm{n}(-)$ & $\mathrm{n}(+)$ \\
\hline Head invasion & 50 & $3(5.7)^{1}$ & & - & - \\
$\quad 0<\mathrm{X} \leq 500$ & 10 & 0 & & 65 & 0 \\
$500 \leq \mathrm{X}<1,000$ & 7 & 0 & & 58 & 0 \\
$1,000 \leq \mathrm{X}<1,500$ & 10 & $1(9.1)^{1}$ & & 46 & $6(11.5)$ \\
$1,500 \leq \mathrm{X}<2,000$ & 6 & $1(14.3)^{1}$ & & 72 & $10(12.5)$ \\
$2,000 \leq \mathrm{X}<2,500$ & 9 & $1(10.0)^{1}$ & & 71 & $13(15.5)$ \\
$2,500 \leq \mathrm{X}<3,000$ & 4 & 0 & & 63 & $8(11.3)$ \\
$3,000 \leq \mathrm{X}<3,500$ & 7 & $2(22.2)$ & & 67 & $5(6.9)$ \\
$3,500 \leq \mathrm{X}$ & 28 & $2(6.7)$ & & 205 & $35(14.6)$ \\
\hline Total & 131 & $10(7.1)$ & 647 & $77(10.6)$
\end{tabular}

Figures in parentheses are percentages.

${ }^{1}$ Vessel invasion, positive.

\section{Pathological Diversity of Cancer and the Correlation between 'Zokushutsu' (Budding/Sprouting) and Lymph Node Metastasis}

The histological features of cancer change and vary as the cancer infiltrates. 'Diversity' means the condition of being diverse or varied. In the Compact Oxford English Dictionary, diversity is explained as difference, oddness, wickedness and perversity. In pathology, diversity can be expressed as 'various', 'polymorphous', 'polyclonal' or 'pluripotential'. A categorization of the meaning of pathological diversity in colorectal cancer would run as follows:

(1) Diversity is apparent in such cancers, since poorly differentiated cancerous lesions are always present, even if they are small. Even though the common types of adenocarcinoma are subclassified according to the most prominent histological characteristic, there are solid and nonsolid types even in poorly differentiated adenocarcinomas, and there are mucous and papillary types even in well-differentiated ones. (2) The fact that squamous cell carcinoma, endocrine cell carcinoma [9], carcinosarcoma, parietal gland carcinoma and rhabdoid features [10], all of which are regarded as uncommon, are present in the common type of adenocarcinoma can be considered indicative of diversity. (3) Varied phenotypic and gene expressions are wide-ranging factors that can be used instead of morphology to characterize cancers.

Digestion 2009;79(suppl 1):40-51 
Why Are Tubular Structures Altered as Infiltration

Progresses?

The infiltration of a cancer into the SM areas (where the invasive front is defined as the deepest area infiltrated) means that the cancer cells are active in these areas. These areas may provide the best conditions for the cancer to survive. What is the most suitable niche?

Kaihara et al. [11, 12] suggested that when poor differentiation and interstitial response occur in the invasive front, the infiltration is associated with metastasis, regardless of whether it is squamous carcinoma or adenocarcinoma of the gastrointestinal (GI) tract. This may be due to weakened cell-cell adhesion by molecules such as E-cadherin. E-cadherin, which is a constituent protein in adherence junctions, is a principal molecule in charge of intercellular adhesion, and attenuation of its membranous expression is reported to be correlated with a decrease in the degree of tumor differentiation and metastasis [11, 12]. Examination of E-cadherin expression by immunostaining of colorectal SM carcinomas in our department also showed that expression was attenuated in about $70 \%$ of cell membranes in the superficial depressed type, whereas attenuation was observed in about $30 \%$ of protruded tumors; the incidence of abnormal Ecadherin expression was significantly higher in the superficial depressed type. E-cadherin expression was also significantly less in lymph node-metastatic colorectal SM carcinomas than in negative cancers. Thus, it is considered that attenuated membranous expression of Ecadherin is associated with readiness for tissue penetration and acquisition of metastatic ability. Flat/depressed type (non-Ip) early colorectal carcinomas are more invasive than Ip types. These results are supported by Mashimo's report.

Metastasis of adenocarcinoma to the liver [13], reduced tubule formation and reduced interstitial response in the deepest infiltrated areas, and weakening of adhesion molecules may also contribute to structural changes in the invasive front of the carcinoma. Kaihara et al. demonstrated that expression of tight junction proteins and tyrosine phosphorylation of epidermal growth factor were related to the re-formation of tubules in metastatic lesions of colorectal cancer in the liver. Signals from growth factors such as epidermal growth factor are activated through tyrosine phosphorylation, cell-cell adhesion with molecules is reduced in the areas infiltrated by adenocarcinoma; this would be associated with metastasis through the destruction of tubular structures, and tubular re-formation in metastatic lesions in the liver occurs as these factors improve. The poorly differentiated lesions found in the invasive front morphologically represent the changes in these series of signals.

\section{How Are Morphologically Collapsed Tubular \\ Structures ('Zokushutsu' in Japanese, Budding/ Sprouting) Infiltrating the Surrounding Sites \\ Described?}

In the GI tract, poor differentiation in the invasive front (meaning the disappearance of tubular structures, not embryological differentiation) is commonly described as budding or sprouting. Tumor cell dissociation, single-cell infiltration, and dedifferentiation are some of the synonyms interchangeably used for this process, and in Japanese we call it zokushutsu/soushutsu.

Imai [14] started using budding/sprouting to describe the infiltration and growth of cancers at the invasive front. He classified the pathological characteristics of invasive areas in tongue, pharyngeal, breast, uterine and GI tract cancers into the following 3 types: elongation type, expanding type and budding/sprouting type. An isolated single cancer cell and a cluster composed of fewer than 5 cancer cells were defined as budding/sprouting foci.

After Imai [14] had released his report, the concept and nomenclature went through changes reported in numerous studies conducted by Yokota et al., Okajima et al., Enjyoji et al., Hayashida et al., Kobayashi et al., Okabe et al., Morotomi et al., Hase et al., Ueno et al., Masaki et al., Chibana et al. and Hori et al. [15]. The results of these studies showed that morphological changes can be associated with metastasis or prognosis.

Budding/sprouting is considered an important parameter in the evaluation of colorectal SM carcinomas. This budding/sprouting has been reported frequently for some time as one of the factors predicting lymph node metastasis in SM invasive colorectal carcinoma.

This evaluation method has merits in that evaluation is possible by ordinary hematoxylin and eosin staining and lymph node metastasis is predictable.

If these points are to be popularized, cases in which cancers are followed over time must be accumulated.

According to Kawachi et al. (projects of the Japanese Society for Cancer of the Colon and Rectum), the results obtained by the Project Committee for Examination of Budding of the Japanese Society for Cancer of the Colon and Rectum were as follows.

Expressions Used for Budding

(1) The Japanese expression has been standardized as zokushutsu/soushutsu.

(2) The expression in English is budding/sprouting. 
Definition of Budding

The definition that 'one budding lesion is an invasive lesion consisting of 4 or fewer individual carcinoma cells, or small cells or tubules with no obvious lymphatic vessel invasion; those for which it is difficult to judge whether or not they are carcinoma cells are excluded' (criteria by Ueno et al.) has been adopted [4].

Method of Measuring Budding

(1) Observations of the invasive front were made.

(2) One field where budding was most intensive was selected.

(3) Budding foci in 1 field were counted in a field measuring $0.385 \mathrm{~mm}^{2}$ using $\times 25$ objective lens.

(4) Cases were graded into 3 groups, grade 1 (budding count $0-4$ ), grade 2 (budding count 5-9) and grade 3 (budding count 10 or more) on the basis of the budding count.

(5) Correction was considered because the actual area of each visual field differed due to the difference in the number of visual fields of 1 microscopic eyepiece used.

\section{Subjects Used for Studying the Significance of}

Budding

Significance of budding as a risk factor for lymph node metastasis was evaluated in patients with invasive SM colorectal carcinoma.

\section{Results and Summary}

In accordance with the above criteria, the results were as follows. When invasive SM colorectal carcinomas were divided into $<1,000 \mu \mathrm{m}$ (slight) and $\geq 1,000 \mu \mathrm{m}$ (massive), lymph node metastasis was found in about $35 \%$ of massive cases with positive budding (grades 2 and 3). Tanaka et al. [16] demonstrated the appropriateness of the above on the basis of surveillance results after endoscopic treatment of invasive SM colorectal carcinoma. Careful reading of the each reference is recommended for details.

\section{Genetic Analysis and Metastasis in the GI Tract}

It is clearly known that phenotypes and genes go through changes as cancers advance, and this has been reported in many studies. These analyses can help in the search for alterations in $a p c, p 53$ or K-ras, which are highly correlated with the formation and progression of cancers and the expression of metastasis-related factors such as cell cycle regulators or adhesion molecules. The K-ras mutation rate in colorectal adenoma is reported to be less than $10 \%$ in adenomas of $\leq 1 \mathrm{~cm}$ and $40-60 \%$ in adeno- mas $>1 \mathrm{~cm}$, and these percentages are similar in another report [17].

Colorectal cancer is less frequent in patients who take nonsteroidal anti-inflammatory drugs, which inhibit cyclooxygenase (COX) enzyme activity [18]. The number of colorectal polyps that developed in apc knockout mice decreased when both alleles of the COX-2 gene were also knocked out [19]. These results imply that the COX-2 gene is involved in colorectal tumorigenesis. COX-2 is overexpressed in up to $43 \%$ of adenomas and $86 \%$ of carcinomas [20]. Furthermore, we have demonstrated that COX-2 is overexpressed in the endocrine cells within colorectal adenomas, and that there is a positive correlation between the number of COX-2-positive endocrine cells and the degree of mutation of the K-ras gene in adenomas [21]. Selective inhibitors of COX-2 are anticipated to help prevent colorectal tumor development [22].

The 'top-down' theory [23] and the term 'ACF' (aberrant crypt foci)-carcinoma sequence [24] are attractive hypotheses for the morphogenesis of colorectal tumor. However, to settle these issues, further studies need to be performed $[25,26]$.

Mutational activation of the K-ras oncogene is considered to play a role in the progression of size and grade of atypia in the adenoma-carcinoma sequence (ACS) [17]. The ras gene is involved in signal transmissions from growth factors, through the tyrosine kinase receptor and mitogen-activated protein kinase, to intranuclear transcriptional factors [27]. When the K-ras gene is mutated, ras protein is constantly activated and continually transmits growth signals to the cells.

In studies of the relationship between the K-ras mutation and the configuration of colorectal tumors, K-ras mutations were detected in up to $70 \%$ of Ip-type tumors (greatest dimension of polyp head $>1 \mathrm{~cm}$ ), whereas these mutations are rare in superficial flat lesions (non-Ip). Therefore, flat colorectal adenocarcinomas are regarded as candidates for de novo carcinogenesis [28-30]. This is because most colorectal carcinomas appear to have a homogeneous composition that may result from the successful progression of one of the clones having a K-ras mutation. Additional mutations in the K-ras gene are rarely observed in colorectal carcinomas [31].

On the other hand, alteration of the $p 53$ gene is not only frequently witnessed in the development of carcinoma through the ACS, but is also shown to be an early and frequent event in de novo carcinogenesis [32]. Alterations of the $p 53$ gene are frequently demonstrated in tumors in various organs, and the functions of this gene are so varied that $p 53$ is called a gatekeeper or guardian of the 
Table 3. Possible $p 53$ status evaluated from the results of $p 53 \mathrm{im}$ munohistochemistry and PCR-SSCP analysis (exons 5-8) [36]

\begin{tabular}{lll}
\hline $\begin{array}{l}\text { IHC } \\
\text { (exons 5-8) } \\
\text { analysis }\end{array}$ & Possible p53 status \\
\hline$(+)$ & mobility shift & missense mutation within exons 5-8 \\
\hline$(+)$ & $\begin{array}{l}\text { no mobility } \\
\text { shift }\end{array}$ & $\begin{array}{l}\text { missense mutation not within exons 5-8; } \\
\text { wild type, but with some abnormalities } \\
\text { of the associated proteins (MDM2, ARF, } \\
\text { viral proteins) }\end{array}$ \\
\hline$(-)$ & $\begin{array}{l}\text { mobility } \\
\text { shift }\end{array}$ & $\begin{array}{l}\text { stop codon-producing mutation within } \\
\text { exons 5-8 [nonsense mutation or frame- } \\
\text { shift (deletion or insertion)] }\end{array}$ \\
\hline$(-)$ & $\begin{array}{l}\text { no mobility } \\
\text { shift }\end{array}$ & $\begin{array}{l}\text { nonsense mutation before exon 5; } \\
\text { missense mutation not within exon 5-8 } \\
\text { at nuclear localization-size; wild type } \\
\text { without any abnormalities of the associ- } \\
\text { ated proteins }\end{array}$ \\
&
\end{tabular}

IHC = Immunohistochemistry; $(+)=$ nuclear staining; $(-)=$ no staining or diffuse cytosolic staining.

genome [33]. The functions of the p53 protein are also varied, one of them being activation of the transcription of certain genes. The target genes identified so far include p21 and cyclin $G$, which are involved in the regulation of the cell cycle. Most $p 53$ mutations occur in exons 5-8 and induce transformation in the DNA-binding region of the p53 protein, resulting in the loss of its transcriptional function. The mutant p53 protein interferes with the DNA-binding function of the wild-type p53 protein (dominant negative effect). There are 2 methods of analyzing $p 53$ alterations in clinically available specimens: one is immunohistochemical demonstration and the other is single-strand conformation polymorphism (SSCP). Histopathological observation is made to determine whether the indefinite lesion is neoplasia or not. For example, we investigated alterations in the $p 53$ gene by using immunohistochemistry in 120 specimens from 8 patients with ulcerative colitis (UC) who had undergone total colectomy for UC-associated neoplasia. The nuclear accumulation rate of the $\mathrm{p} 53$ protein was $0 \%(0 / 5$ specimens) in UC-I (almost normal mucosa), $0 \%$ (0/38 specimens) in UC-IIa (atypical epithelium, probably regenerative), $40.0 \%$ (14/35 specimens) in UC-IIb (atypical epithelium, probably neoplastic), $58.3 \%$ (14/24 specimens) in UC-III (low-grade dysplasia and low-grade intraepithe- lial neoplasia) and 61.1\% (11/18 specimens) in UC-IV (high-grade dysplasia and adenocarcinoma: high-grade intraepithelial neoplasia including noninvasive and invasive adenocarcinoma). In UC patients with no dysplasia or cancer, there was no demonstrable abnormal nuclear accumulation of p53 protein. However, multiple alterations of the $p 53$ gene occur in a diverse range of colorectal cancers, unlike the case with the K-ras mutation.

Negative staining for the $\mathrm{p} 53$ protein does not always indicate normality of the $p 53$ gene. When the $p 53$ gene has a nonsense mutation or frameshift, $\mathrm{p} 53$ protein does not accumulate in the nucleus, despite the gene abnormality. Therefore, we investigated alterations in the $p 53$ gene in 43 specimens by using polymerase chain reaction (PCR)-SSCP analysis within exons 5-8 [34, 35]. Of the specimens that showed negative immunohistochemical staining for p53, thirty-three were included in the PCRSSCP analysis. The proportions shown to be positive for p53 mutation were $0 \%$ (0/2 specimens) of UC-I, $20.0 \%$ ( $2 / 10$ specimens) of UC-IIa, $71.4 \%$ (5/7 specimens) of UCIIb, $85.7 \%$ (7/8 specimens) of UC-III and $100 \%$ (6/6 specimens) of UC-IV. This result suggests that analysis of the p53 mutation by using PCR-SSCP is more accurate than immunohistochemistry for discrimination between UCassociated neoplasia and regenerative epithelium. This technique should be adopted for the accurate pathological diagnosis of UC-associated neoplasia.

However, conventional analysis of limited regions of the $\mathrm{p} 53$ protein is not sufficient for evaluating the actual events that occur in tumorigenesis. Negative staining and negative mutation do not always mean that the $p 53$ pathway is functioning normally (table 3) [36].

\section{Summary}

In families with a history of hereditary colon tumors, preclinical diagnosis can be conducted by detecting abnormalities in the $a p c$ or mismatch repair gene. Currently, thorough analysis of gene expression is conducted in various types of GI tract cancer by using microarray technology. Furthermore, a project that is trying to reveal sensitivity to carcinogenesis by detecting single nucleotide polymorphisms or differences in drug sensitivity in hosts is under way. It is impossible to classify tumors not depending on abnormality in certain genes but according to the expression patterns of multiple genes by detection using this type of genomics. Moreover, a useful database is likely to be created from the accumulated information. For example, there are cancer lesions that potentially metastasize and do not metastasize even if their forms are the same. With the current diagnostic procedures used to determine cancer morphology it is difficult to distinguish those cancer cells that have the ability to metastasize and infiltrate.

Kawamata et al. [1] subcloned cells that easily infiltrate in vitro by using T.Tn cells that were basically less likely to metastasize and attempted to transplant these 2 types of cells into animal 
models by using orthotopic transplantation [37]. After they empirically confirmed that one cell type metastasized and the other ones did not, the 2 gene expression profiles were compared. Some differences were found in gene expression. On the basis of these profiles, investigations have been made into some genes from the perspective of metastatic potential. For example, the expression patterns of the gene encoding CXCR4, one of the cytokines [38], have been compared in cancer lesions with 5-year survival rates in both esophageal and colorectal cancer [39]. These comparisons were just 1 example of clinical application of the diversity of gene abnormalities in cancer.

Pathological and genetic diversity is not specific to colorectal cancer; it is commonly observed in any cancer lesion. Analysis of these changes may help us to develop suitable treatment options and predict their effects on the basis of the most accurate diagnosis of cancer that is possible. If cancer cells do indeed function as pluripotential cells during differentiation, then we can expect further studies based on the concepts of epithelial-mesenchymal transformation, niches for cancer stem cells and cancer-associated stromal fibroblasts [40].

\section{Conditions Requiring Resection after Endoscopic Treatment}

Additional colectomy with lymph node dissection after endoscopic resection of an invasive SM colorectal carcinoma is explained in the General Rules for Clinical and Pathological Studies on Cancer of the Colon, Rectum and Anus (7th edition) [41]. These rules state that lymph node metastasis is likely to occur when the presence of 1 or more of the following is detected: (a) an obvious lymphovascular invasion by carcinoma; (b) a poorly differentiated adenocarcinoma or undifferentiated carcinoma; (c) a massive carcinoma invasion of the vicinity of the stump.

However, even when an additional colectomy is performed on the basis of these risk factors, lymph node metastasis is actually found at a rate of only about $10 \%$ and, furthermore, the additional risk factors for detection of lymph node metastasis have been considered. Consensus has almost been reached in regard to (a) and (b) mentioned above, although there are still problems such as deciding on the best method for accurate histological evaluation of lymphovascular invasion in the former, and determining the ratio occupied by a poorly differentiated adenocarcinoma or undifferentiated carcinoma, as well as the depth of invasion, in the latter. In contrast, (c) is quite an ambiguous expression; the General Rules for Clinical and Pathological Studies on Cancer of the Colon, Rectum and Anus (6th edition) gives 'deeper submucosal invasion' as a requirement for additional resection. Although numerous studies have been conducted to determine the depth to which invasion can occur without lymph node metastasis, they have all had problems, such as 'inappropriate baseline for measurement', 'inconsistent results' and 'small number of cases examined'.

Therefore, the project committee of the Japanese Society for Cancer of the Colon and Rectum for handling invasive SM colorectal carcinomas (diagnosed from specimens treated by polypectomy, endoscopic mucosal resection, endoscopic SM dissection or surgical resection) has collected 865 cases of invasive SM carcinomas of the colon and rectum [3]. In the analysis, invasive SM colorectal carcinomas were classified endoscopically into Ip and non-Ip. The analytical findings can be summarized as follows. None of the patients with non-Ip-type invasive SM colorectal carcinoma had lymph node metastasis when the depth of SM invasion was $\leq 1,000 \mu \mathrm{m}(1 \mathrm{~mm})$. None of the patients with Ip-type invasive SM colorectal carcinoma had lymph node metastasis either, provided that the lymphatic vessels were negative for invasion and the depth of SM invasion was $\leq 3,000 \mu \mathrm{m}$ (table 2).

\section{Summary}

The process of cancer metastasis begins with vascular invasion [42]. If Ip SM cancers are negative for vascular invasion and at the vertical resection margin, the endoscopic indications may be able to be expanded to an SM depth of 3,000 $\mu \mathrm{m}$ (stalk invasion). Specialized excision devices and the routinization of special staining are needed. It is important to know that D2-40 antibody staining, which is effective for the detection of lymphatic invasion, is also positive in myoepithelium; sometimes a misdiagnosis of lymphatic invasion is made [43]. The capacity of Ip-type high-grade adenomas for pseudoinfiltration should not be overestimated.

\section{Improvement of Methods Used to Measure Depth of SM Invasion in the Ip Type}

\section{The General Rules for Clinical and Pathological Studies} on Cancer of the Colon, Rectum and Anus were revised as the 7th edition 3 years after publication of the 6th edition and the Guidelines for the Treatment of Colorectal Carcinoma were newly published in 2005 . The rules (by Kitajima's reference) have demonstrated the practical issues associated with actual measurement of the depth of invasion of invasive SM colorectal carcinoma. They may be summarized into 2 points: one is the handling of cases of the non-Ip type with a discontinuous muscularis mucosae and the other is interpretation of the method of measuring Ip lesions. In regard to the former, there have been cases in which measurement has been performed by connecting the discontinuous traces of muscularis mucosae remaining after destruction by the cancer invasion and 
Fig. 1. The method for measurement of SM depth. a For Ip, maintained muscularic mucosae as the baseline; measuring from this line. b For Ip with head invasion; measuring from the baseline. c For non-Ip, maintained muscularis mucosae as the baseline; measuring from this line. d For non-Ip, destructed muscularis mucosae; measuring from surface of tumor. $\mathrm{MM}=$ Muscularis mucosae; $\mathrm{MP}=$ muscularis propria.

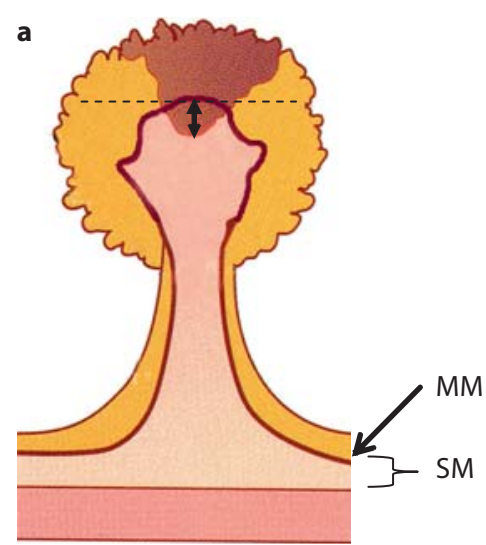

b
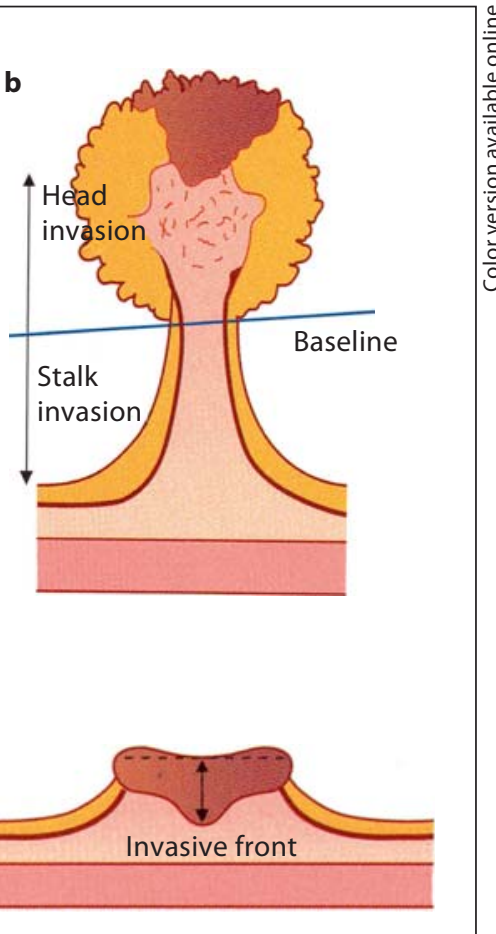

thereby identifying the muscle plate unreasonably. It was advised that there would be no need to draw a continuous line by fabricating the destroyed muscularis mucosae, even though it was possible to assume a line in continuous form. It would instead be favorable to measure from the surface, since patients with destruction of the muscularis mucosae are at high risk of lymph node metastasis. In many cases this issue seems to have been solved by the application of such concepts.

The method of drawing the baseline for Ip lesions, on the other hand, needs amendment in the revised version of the General Rules for Clinical and Pathological Studies on Cancer of the Colon, Rectum and Anus. The baseline for the Ip type must be explained again, although it has already been explained before. (1) In a case with a clear muscularis mucosa, the depth of invasion is measured from its lower end (the bottom of the muscularis mucosae), even if the case is an Ip type. (2) The depth of invasion must be measured from the baseline drawn according to the prescribed rules only in Ip types in which the muscularis mucosae is complicated by head invasion (fig. 1).

Clarification of Confusion about the Terms Related to Level of SM Carcinoma Invasion

For the classification of SM carcinoma invasion, there are classification systems devised by Kudo et al. [44],
Haggitt et al. [45] and Kikuchi et al. [46], as well as Kitajima's classification already mentioned above.

Classifications by Kudo et al. and Kikuchi et al.

The classification of Kudo et al. [44] is a method that divides the SM depth equally from the lower end of the muscularis mucosa to the upper end of the muscularis propria into 3 parts, $\mathrm{sm} 1, \mathrm{sm} 2$ and $\mathrm{sm} 3$, and classifies the carcinoma by the degree of expansion $(a, b$ and $c)$ within the submucosa. The classification of Kikuchi et al. [46] uses the term 'level of invasion' and defines $\mathrm{sm} 1$ as slight SM invasion (invasion of 200-300 $\mu \mathrm{m}$ depth in the submucosa from the lower end of the muscularis mucosa) and $\mathrm{sm} 3$ as invasion into the vicinity of the upper end of the muscularis propria. $S \mathrm{~m} 2$ is at a level in between.

\section{Haggitt's Classification}

Haggitt's classification was described in a paper contributed to Gastroenterology in 1984 [46] and was based on specimens resected endoscopically. The system sets up zones based on the relationship with anatomical positions and assesses the zone reached by carcinoma invasion in terms of levels. The issue associated with this classification system is the conclusion that carcinoma with a level 4 invasion classification has a poor prognosis, but level 4 differs between the Ip type and the sessile type. 
That is to say, according to Haggitt's analysis, carcinomas of the flat or depressed type with very slight SM invasion are all classified as level 4; this results in inconsistency in that they are handled in the same way as level 4 SM carcinomas of the Ip type with stalk invasions. Haggitt et al. [46] might not have seen these former types of cases, although this is only a guess, because no detailed case history data were given in their paper. Another issue is that level 2, expressed as 'neck' by Haggitt et al. [46] is defined not as a line but as an ambiguous, broad region.

\section{Summary}

The range of indications for endoscopic treatment for colorectal SM carcinoma is tending to expand. However, colorectal SM carcinoma is a lesion with metastatic potential. Therefore, importance must be attached to the pathological evaluation of this lesion.

Previous classifications of colorectal SM carcinoma were ambiguous; such methods were especially not useful for patients treated by endoscopy, because the specimens examined in these cases do not have a muscularis propria.

For the application of these data, it is essential to clinically differentiate whether or not the lesions are of Ip type. On diagnostic endoscopy, it is essential to fully consider the influences of such factors as gravity, folds and air volume on lesion appearance in order to carefully differentiate between Ip and non-Ip lesions. Moreover, tissue preparations made after endoscopic resection may be variously modified and may often not be representative of the original macroscopic appearance. Therefore, it is advisable not to presume the macroscopic type from the appearance of a specimen that has been stained with hematoxylin and eosin for microscopic diagnosis

\section{Japanese Morphological Classification of Colorectal Neoplastic Lesions in Terms of the Clinical Pathology and Genetics of LSTs}

As stated before, the patterns of development of colorectal tumors and related gene abnormalities have been analyzed. The pathways presumed today include that of the common cancerization of adenomas (ACS type), the de novo type (flat cancers are candidates for this type), the hereditary nonpolyposis colorectal cancer (HNPCC) type and inflammatory bowel disease-related cancer. The pathways by which LSTs, discussed here, and villous tumors become cancerous are unknown at present.

\section{Laterally Spreading Tumors}

The morphological classification of colorectal neoplasias is based simply on macroscopic 'shapes', and it is stated in the General Rules for Clinical and Pathological
Studies on Cancer of the Colon, Rectum and Anus that type O (superficial type) tumors are classified macroscopically into the protruded type (I) and superficial type (II) on the basis of the endoscopic findings; the shape of the lesion is considered to give the whole picture without considering the histogenesis or differences between tumor and nontumor. The former is then subclassified into pedunculated type (Ip), subpedunculated type (Isp) and sessile type (Is), and the latter into superficial elevated type (IIa), superficial flat type (IIb) and superficial depressed type (IIc). On the other hand, Kudo et al. have proposed the LST as a macroscopic type characterized by features other than macroscopic morphology $[2$, 47]. Although LSTs are often classified into IIa or IIa + IIc according to the rules based simply on shape, the tumors that clinicians would think should be classified as LSTs have certain features. For example, the LST granular type (LST-G), which is a nodule-aggregating lesion, is often considered suitable for endoscopic treatment, even if the tumor is large. Similarly, the adenoma or M carcinoma of nongranular LST (LST-NG), which is discriminated from IIa by the presence of infiltrating cancer in the nodules of the mixed-nodule type, smoothness and absence of granular or nodular aggregation, and pseudopodia, is often suitable for endoscopic therapy. The frequency of SM carcinoma is increased in LST-NG with a tumor diameter exceeding $20 \mathrm{~mm}$, suggesting possible multifocal infiltration, especially in the pseudodepressed type. Under the macroscopic classification according to the rules, the Ip + IIc lesion can be seen as a superficial de novo cancer presenting with a pedunculated form and the Is + IIc lesion can be seen as a superficial de novo cancer infiltrating the submucosa. Thus, tumor characteristics other than shape (for example developmental process) are incorporated into these morphological classifications.

The ACS type, HNPCC type and de novo type describe routes of onset of sporadic colorectal cancers. Apart from these, the dysplasia-carcinoma sequence, an onset route associated with inflammatory bowel disease, is known to exhibit a variety of macroscopic morphologies. ACS-type carcinogenesis is cancerization through adenoma, and many sporadic colorectal carcinomas are considered to cancerate by this route. In the process, mutations in the APC gene, K-ras gene and $p 53$ gene occur stepwise in the occurrence, growth and cancerization of adenoma. It is known that HNPCC-type carcinogenesis is caused by microsatellite instability (MSI) when the DNA repair genes $h M L H 1$ and $h M S H 2$ cannot repair abnormalities in MSI that occur during DNA repair; 10- 
$15 \%$ of sporadic colorectal cancers are said to cancerate by this process. Cancers of this type occur most frequently in the right colon and are characterized by the histological types of poorly differentiated adenocarcinoma and mucinous carcinoma. The de novo type (the superficial depressed type) does not contain adenoma components, although its incidence or the nature of its early lesions have not been clarified; these are recognized as cancers with a deep penetrating tendency, even if the tumor diameter is small. A p53 gene abnormality is involved in the onset of de novo cancers, similarly to ACS-type carcinogenesis, but K-ras mutation rates are low in these cancers and an association with abnormalities in intercellular adhesion molecules has been reported.

This discussion is based on the results of clinicopathological examination and molecular biological examination, including analyses of K-ras mutation, $p 53$ gene abnormality and E-cadherin expression, in a total of 239 lesions of colorectal adenoma and early colorectal cancers of various macroscopic types [159 cases with elevated tumors (Ip, Isp, Is), 57 with superficial elevated-type tumors (IIa, IIa + IIc), 28 with superficial depressed-type tumors (IIc, IIc + IIa), 58 with LST-G and 63 with LST-NG]. Our conclusions were that current molecular biological examinations classified LSTs into 2 groups: many adenoma-containing lesions were ACS-type tumors with similarities to LST-G, whereas non-adenoma-containing lesions were often de novo-type tumors with similarities to the superficial depressed type. LST-NG lesions were also classified into 2 groups, and the group of tumors $<20 \mathrm{~mm}$ in diameter contained those with similarities to the superficial depressed type. Thus, at least LST-G and LST-NG could be further divided into 2 subgroups by developmental and morphological classification taking developmental patterns and genetic abnormalities into consideration.

On the other hand, Sugai et al. have collected tumor glands by using a crypt isolation technique and have performed DNA analysis of these tumors. Using PCR-LOH, $\mathrm{LOH}$ at $5 \mathrm{q}, 17 \mathrm{p}, 18 \mathrm{q}$ and $1 \mathrm{p}$ was analyzed. They investigated the presence of MSI in BAT25 and BAT26. They concluded that the molecular mechanisms of LST-NG differed from those of adenomas, and they emphasized the specificity of LST-NG, as we did.

Many LST-NG lesions maintained membranous Ecadherin expression and the lesions showing attenuation of E-cadherin expression all had diameters between 10 and $<20 \mathrm{~mm}$. Thus, LST-NG $<20 \mathrm{~mm}$ in diameter were also similar to superficial depressed-type tumors in terms of E-cadherin expression pattern. This result suggests that there can be a mixture of deep penetrating tumors in small LST-NG lesions, similarly to the case in the superficial depressed type.

\section{Summary}

The macroscopic classification in the General Rules for Clinical and Pathological Studies on Cancer of the Colon, Rectum and Anus is acceptable simply on the basis of shape, without the integration of developmental and morphogenetic classifications. However, the classification of LSTs on the basis of these clinical characteristics seemed useful for endoscopists.

\section{Villous Tumors}

\section{Definition of Villous Adenoma}

According to the General Rules for Clinical and Pathological Studies on Cancer of the Colon, Rectum and Anus, colorectal adenomas are classified into tubular adenomas (TAs), tubulovillous adenomas (TVAs) and villous adenomas (VAs). Our department classifies colorectal adenoma into 3 types histologically by the percentages of the villous component and tubular component in the entire tumor: VA if the villous component is present in $>75 \%$ of the tumor, TA if the villous component is present in $<25 \%$ of the tumor and TVA if the villous component is present in 25$75 \%$ of the tumor. Here, the villous component is defined as a structure in which villous processes histologically stretch straight from the muscularis mucosae to the lumen, the processes are more than 3 times the height of the mucosa, the amount of interstitium in the process is small and the epithelium covering the process is often straight and rarely associated with duct budding.

\section{Molecular and Pathological Examination of VA \\ $\mathrm{K}$-ras}

In an examination of colorectal adenomas classified into each histological type, K-ras mutation was seen more frequently in TVAs and VAs than in TAs. An examination conducted by our department showed that the K-ras mutation frequency was as low as $5 \%$ or less in TAs but about $50 \%$ in TVAs and about $70 \%$ in VAs. Tumor diameter in TVA and VA is larger than in TA, and the K-ras mutation results seem dependent on tumor diameter. However, in terms of histological type, K-ras mutation frequency was low in TVAs of larger diameter but composed mainly of the tubular component, whereas it was high in larger tumors with a greater villous component. Considering that the K-ras mutation of VAs was more frequent than that of TVAs, the K-ras mutation of TVAs is likely to be heterogeneous. K-ras mutation of TVAs with a smaller villous component may become negative, 
because it can be undetectable by PCR-RFLP; K-ras mutation may therefore be more common in the villous component than in the tubular component.

\section{p53}

In an immunohistological analysis of the $\mathrm{p} 53$ protein, many VAs were negative or showed a sporadic pattern despite their large diameters, and fewer than $10 \%$ of cases had a focal pattern. However, about $30 \%$ of TVAs coincided with focal cancer or high-grade adenoma and had a focal pattern of $\mathrm{p} 53$ positivity.

According to the report by Rashid et al. [48], 20\% of TVAs showed abnormal p53 protein accumulation, whereas no abnormal accumulation was observed in VAs, although only 2 cases were examined. Also, Yao et al. [49] reported that abnormal p53 protein accumulation was seen in $12 \%$ of VAs. p53 was immunohistologically examined in SM and advanced cancers with a villous structure; the p53 staining patterns in all cases were sporadic or negative, and no specimens showed a focal or a diffuse pattern.

\section{Mucus Expression}

Human gastric mucin (HGM) expressed on the crypt epithelium of the gastric corpus and antrum is also known to be expressed in colorectal adenoma and some types of colorectal cancer. In an evaluation of HGM expression in colorectal adenoma by immunostaining, HGM was strongly expressed in all TVA and VA cases and was negative or slightly positive in TAs. In the TVAs, expression was weakened at sites of severe atypia or cancer, and the mucus expression was changed by elevation in the degree of atypia and by oncogenic transformation. Moreover, almost no HGM expression was observed in advanced cancers, except in the case of mucinous carcinoma. Therefore, HGM is temporarily expressed in the process of the ACS, and its expression diminishes as the degree of atypia increases.

In VAs, HGM expression diminishes as the degree of atypia rises, in the same way as in TVAs, but cell atypia is mild or moderate. In many VA cases the tumor diameter increases, and HGM expression remains strong in such tumors. MUC2 expressed on the normal colorectal epithelium is strongly expressed in TAs, TVAs and VAs, but, as with HGM, its expression in TVAs diminishes as atypia increases.

\section{Proliferative Activity and Apoptosis}

Arai et al. [50] reported that the mitotic index in VAs is equivalent to that of TA with mild atypia and is not high, but that the apoptotic index in VA is significantly lower than that in TA, giving a large tumor diameter, and that bcl-2 expression in TVAs and VAs was significantly greater than in TAs.

In an examination of proliferative activity conducted by our department using Ki-67 immunostaining, proliferative activity was distributed in all layers of VAs but not in TVAs, but the labeling index was low in VAs. Labeling index tended to increase with increasing tumor diameter in TVAs but not in VAs.

\section{Pathways of Development of VA}

Initial Lesion of VA

Tumor diameter in VA is almost always $>15 \mathrm{~mm}$. VAs $<15 \mathrm{~mm}$ are very rarely observed, and ones $<10 \mathrm{~mm}$ are virtually never observed; adenomas $<10 \mathrm{~mm}$ are TAs or TVAs. Thus, the initial lesions of VAs are TAs or TVAs; TAs and TVAs are considered to acquire their villous structure in the process of proliferation to become VAs.

Advanced Cancer Associated with Villous Structure

What kind of gross morphology is observed when VAs transform into cancers and invade deeply to become advanced cancers? First, one of the advanced cancers associated with the villous structure is mucinous carcinoma. Some mucinous carcinomas have a villous component on their margins, and transition from VAs is assumed morphologically. In an evaluation of mucinous carcinoma by our department, all mucinous carcinomas with a villous component on their margins showed negative or sporadic patterns of p53 immunostaining, and many of them were K-ras codon 12-point mutation positive. Also, in HGM immunostaining, both the villous component and the mucinous component in the central parts of the tumors showed strong expression of HGM.

\section{Summary}

We have discussed how the initial lesion of the VA is a tiny TA or TVA, because VAs $<1 \mathrm{~cm}$ are very uncommon. Mucinous carcinomas with villous structures resemble VAs in terms of molecular pathology, because they have a high frequency of K-ras mutation and display negative or sporadic expression of $p 53$ gene products and overexpression of HGM. It is possible that mucinous carcinoma, with villous structures, is derived from VA.

\section{Acknowledgements}

The authors thank Dr. H. Kawamata (Department of Oral and Maxillofacial Surgery, Dokkyo Medical University, Tochigi, Japan), Dr. T. Sugai (Division of Pathology, Iwate Medical University, Morioka, Japan), Dr. K. Matsuda (Department of Orthopaedic Surgery, Teikyo University School of Medicine, Tokyo, Japan), 
Dr. S. Tamura (Department of Gastroenterology and Hepatology, Kochi Medical School, Nankoku, Japan), Dr. N. Maruyama (Department of Gastroenterology, Fujita Health University, Toyoake, Japan), Dr. H. Kawachi (Department of Pathology, Graduate School of the Tokyo Medical and Dental University, Tokyo, Japan), Dr. S. Kazama (Department of Surgical Oncology, University of Tokyo Hospital, Tokyo, Japan), Dr. H. Ueno (Department of Surgery, National Defense Medical College, Tokorozawa, Japan), Dr. M. Yasuda (Kagawa Prefectural Cancer Detection Center, Kagawa, Japan), Dr. Y. Mashimo (Department of Gastroenterology, National Cancer Center Hospital, Tokyo, Japan), Dr. K. Kitajima (Third Department of Internal Medicine, Oita University Faculty of Medicine, Oita, Japan) for fruitful discussions. We also thank our colleagues and staff members, Dr. K. Suzuki, Dr. A. Sekikawa, Dr. K. Ichikawa, Dr. S. Tomita, Dr. H. Fukui, Dr. J. Imura, Dr. H. Sato, Dr. H. Yamagishi, Dr. T. Kimura, Dr. H. Tanaka, Dr. H. Ogata, Ms. C. Matsuyama, Ms. A. Shimizu, Ms. T. Ono,
Ms. M. Katayama, Ms. N. Nagashima (Department of Pathology) and Dr. K. Akiyama, Ms. S. Miyahara, Ms. M. Ishikawa (Department of Biological Psychiatry and Neuroscience) for expert advice and technical assistance. All drafts of the manuscript were typed by Ms. Atsuko Kikuchi.

The contents of this review have already been published as original articles and are compiled as a record of the core symposium of the 4th annual meeting of the Japanes Gastroenterological Association.

\section{Disclosure Statement}

The authors declare that no financial or other conflict of interest exists in relation to the content of the article.

\section{References}

1 Kawamata H, Tachibana M, Fujimori T, Imai Y: Differentiation-inducting therapy for solid tumors. Curr Pharm Design 2006;12:379385 .

2 Kudo S: Endoscopic mucosal resection of flat and depressed types of early colorectal cancer. Endoscopy 1993;25:455-461.

-3 Kusaka T, Fukui H, Sano Y, Ueda Y, Chiba T, Fujimori T: Analysis of K-ras codon 12 mutations and p53 overexpression in colorectal nodule-aggregating tumors. J Gastroenterol Hepatol 2000;15:1151-1157.

4 Kitajima K, Fujimori T, Fujii S, Takeda J, Ohkura Y, Kawamata H, Kumamoto T, Ishiguro S, Kato Y, Shimoda T, Iwashita A, Ajioka Y, Watanabe H, Watanabe T, Muto T, Nagasako $\mathrm{K}$ : Correlations between lymph node metastasis and depth of submucosal invasion in submucosal invasive colorectal carcinoma: a Japanese collaborative study. J Gastroenterol 2004;39:534-543.

$\checkmark 5$ Ueno H, Murphy J, Jass JR, Mochizuki H, Talbot IC: Tumour 'budding' as an index to estimate the potential of aggressiveness in rectal cancer. Histophathology 2002;40:127132.

6 Masaki T, Matsuoka H, Sugiyama M, Abe N, Atomi Y, Sakamoto A: New prognostic markers in submucosally invasive colorectal carcinomas: clinical implication of tumor budding; in Muto T, Mochizuki H, Masaki T (eds): Tumor Budding in Colorectal Cancer. New York, Nova Science Publishers Inc., 2006, pp 139-150.

7 Nishi M, Moriyasu F: Clinicopathological study for reevaluation of the depth of submucosal invasion and histological classification of early colorectal cancer (in Japanese with English abstract). Jpn J Gastroenterol 2002; 99:769-778.
8 Matsuda T, Fujii T, Ikehara H, Kouzu T, Kadokawa Y, Kobayashi M, Ohtake Y, Ohno A, Ikematsu H, Uraoka T, Furuya T, Hasuda K, Hotta K, Oda I, Gotouda T, Yamaguchi H, Saito D, Saito Y: Ip Isp type early colorectal cancer - diagnosis of depth of invasion for selection of treatment modality (in Japanese with English abstract). Stomach Intest 2002; 37:1559-1570.

9 Nishikura K, Watanebe H, Iwafuchi M, Ajioka Y, Hashidate $H$, Tanabe T, Shiroshita $H$ Aihara R, Kijima H: Historical overview of the classification of gastric carcinoid (in Japanese with English abstract). Stomach Intest 2000;35:1349-1354

10 Kono T, Imai Y, Imura J, Ono Y, Hagiwara S, Taira K, Fujita M, Tsubaki M, Sunagawa M, Fujimori T: Cecal adenocarcinoma with prominent rhabdoid feature: report of a case with immunohistochemical, ultrastructual and molecular analyses. Int J Surg Pathol 2007;15:414-420.

11 Kaihara T, Kawamata H, Imura J, Fujii S, Kitajima K, Omotehara F, Maeda N, Nakamura T, Fujimori T: Redifferentiation and ZO-1 reexpression in liver-metastasized colorectal cancer: possible association with epidermal growth factor receptor-induced tyrosine phosphorylation of ZO-1. Cancer Sci 2003. 94:166-172.

12 Kaihara T, Kusaka T, Nishi M, Kawamata H, Imura J, Kitajima K, Itoh-Minami R, Aoyama N, Kasuga M, Oda Y, Hattori M, Fujimori T: Defferentiation and decreased expression of adhesion molecules, E-cadherin and ZO-1, in colorectal cancer are closely related to liver metastasis. J Exp Clin Cancer Res 2003;22:117-123.

13 Hirohashi S: Inactivasion of the E-cadherinmediated cell adhesion system in human cancers. Am J Pathol 1998;153:333-339.
14 Imai T: Growth patterns in human carcinoma: their classification and relation to prognosis. Obstet Gynecol 1960;16:296-308.

15 Ichikawa K, Fujimori T, Chibana Y, Fujii S, Iida M, Ohkura Y, Hori H, Kuroda Y, Sakai Y: In the field of gastrointestinal pathology; in Muto T, Mochizuki H, Masaki T (eds): Tumor Budding in Colorectal Cancer. New York, Nova Science Publishers Inc., 2006, pp 3-13.

16 Tanaka S, Haruma K, Oh-E H, Nagata S, Hirota Y, Furudoi A, Amioka T, Kitadai Y, Yoshihara M, Shimamoto F: Conditions of curability after endoscopic resection for colorectal carcinoma with submucosally massive invasion. Oncol Rep 2000;7:783-788.

17 Vogelstein B, Fearon ER, Hamilton SR, Kern SE, Preisinger AC, Leppert M, Nakamura Y, White R, Smits AM, Bos JL: Genetic alterations during colorectal tumor development. N Engl J Med 1998;319:525-532.

18 Thun MJ, Namboodiri MM, Heath CW Jr: Aspirin use and reduced risk of fatal colon cancer. N Engl J Med 1991;325:1593-1596.

19 Oshima M, Dinchuk JE, Kargman SL, Oshima H, Hancock B, Kwong E, Trzaskos JM, Evans JF, Taketo MM: Suppression of intestinal polyposis in APC delta 716 knockout mice by inhibition of cycloxygenase 2 (COX2). Cell 1996;87:803-809.

$\checkmark 20$ Eberhart CE, Coffey RJ, Radhika A, Giardiello FM, Frerrenbach S, Dubois RN: Upregulation of cyclooxygenase 2 gene expression in human colorectal adenomas and adenocarcinomas. Gastroenterology 1994; 107:1183-1188.

21 Fujita M, Fukui H, Kusaka T, Morita K, Fujii S, Ueda Y, Chiba T, Sakamoto C, Kawamata H, Fujimori T: Relationship between cyclooxygenase (COX)-2 expression and K-ras gene mutation in colorectal adenomas. J Gastroenterol Hepatol 2000;15:1277-1281. 
-22 Mukawa K, Fujii S, Tominaga K, Toshitake N, Abe A, Kono T, Sekikawa A, Ichikawa K, Tomita S, Imura J, Ono Y, Shinoda M, Hiraishi $\mathrm{H}$, Fujimori T: Inhibitory effects of the cyclooxygenase- 2 inhibitor, etodolac, on colitis-associated tumorigenesis in p53-deficient mice treated with dextran sulfate sodium. Oncol Rep 2008;19:393-399.

-23 Shih IM, Wang TL, Traverso G, Romans K, Hamilton SR, Ben-Sasson S, Kinzler KW, Vogelstein B: Top-down morphogenesis of colorectal tumors. Proc Natl Acad Sci USA 2001;98:2640-2645.

-24 Takayama T, Katsuki S, Takahashi Y, Ohi M, Nojiri S, Sakamaki S, Kato Y, Kogawa K, Miyake H, Niitsu Y: Aberrant crypt foci of the colon as precursors of adenoma and cancer. N Engl J Med 1998;339:1277-1284.

-25 Fujimori T, Fujii S, Kitajima K, Nishi M, Sano Y: Initial transformed cells of colorectal adenoma: do they occur at the top of the crypt? J Gastroenterol 2002;37:982-984.

26 Takeda J, Kawamata H, Fujimori T: Is the term 'ACF' necessary in humans? J Gastroenterol 2004;39:400-401.

27 Pronk GJ, Bos JL: The role of p21ras in recep tor tyrosine kinase signalling. Biochim Biophys Acta 1994;1198:131-147.

-28 Fujimori T, Satonaka K, Yamamura-Idei Y, Nagasako K, Maeda S: Non-involvement of ras mutations in flat colorectal adenomas and carcinomas. Int J Cancer 1994;57:5155.

-29 Fujimori T, Ono Y, Sakuma K, Ueda Y, Terano A: Genetic changes in colorectal adenoma and cancer in relation to various morphologic aspects. J Gastroenterol 1998;33:804-810.

-30 Goto H, Oda Y, Murakami Y, Tanaka T, Hasuda K, Goto S, Sasaki Y, Sakisaka S, Hattori M: Proportion of de novo cancers among colorectal cancers in Japan. Gastroenterology $2006 ; 131: 40-46$.
31 Ishii M, Sugai T, Habano W, Nakamura S: Analysis of Ki-ras gene mutations within the same tumor using a single tumor crypt in colorectal carcinomas. J Gastroenterol 2004; 39:544-549.

32 Yukawa M, Fujimori T, Maeda S, Tabuchi M, Nagasako K: Comparative clinicopathological and immunohistochemical study of ras and p53 in flat and polypoid type colorectal tumors. Gut 1994;35:1258-1261.

33 Levine AJ: p53, the cellular gate-keeper for growth and division. Cell 1997;88:323-331.

34 Fujii S, Katsumata D, Fujimori T: Limits of diagnosis and molecular markers for early detection of ulcerative colitis-associated colorectal neoplasia. Digestion 2008;77:212

35 Fujii S, Fujimori T, Chiba T: Usefulness of analysis of p53 alteration and observation of surface microstructure for diagnosis of ulcerative colitis-associated colorectal neoplasia. J Exp Clin Cancer Res 2003;22:107-115.

36 Fujimori T, Kawamata H, Kashida H: Precancerous lesions of the colorectum. J Gastroenterol 2001;36:587-594.

-37 Furihata T, Sakai T, Kawamata H, Omotehara F, Shinagawa Y, Imura J, Ueda Y, Kubota K, Fujimori T: A New in vivo model for studying invasion and metastasis of esophageal squamous cell carcinoma. Int J Oncol 2001;19:903-907.

38 Yoshitake N, Fukui H, Yamagishi H, Sekikawa A, Fujii S, Tomita S, Ichikawa K, Imura J, Hiraishi H, Fujimori T: Expression of SDF$1 \alpha$ and nuclear CXCR4 predicts lymph node metastasis in colorectal cancer. Brit J Cancer 2008;98:1682-1689.

39 Zeelenberg IS, Ruuls-Van Stalle L, Roos E: The chemokine receptor CXCR4 is required for outgrowth of colon carcinoma micrometastases. Cancer Res 2003;63:3833-3839.

40 Hwang RF, Moore T, Arumugam T, Ramachandran V, Amos KD, Rivera A, Ji B, Evans DB, Logsdon CD: Cancer-associated stromal fibroblasts promote pancreatic tumor progression. Cancer Res 2008;68:918-926.
41 Japanese Society for Cancer of the Colon and Rectum (ed): General Rules for Clinical and Pathological Studies on Cancer of the Colon, Rectum and Anus (ed 7). Japanese Classification of Colorectal Carcinoma. Tokyo, Kanehara, 2006.

42 Fidler IJ: Critical factors in the biology of human cancer metastasis: twenty-eighth G.H.A. Clowes memorial award lecture. Cancer Res 1990;50:6130-6138.

43 Rabban JT, Chen YY: D2-40 expression by breast myoepithelium: potential pitfalls in distinguishing intralymphatic carcinoma from in situ carcinoma. Hum Pathol 2008; 39:175-183.

44 Kudo S, Soga J, Yamamoto M, Koyama S Muto T: Treatment of colorectal sm- carcinomas (in Japanese with English abstract). Stomach Intest 1984;19:1349-1355.

45 Haggitt RC, Glotzbach RE, Soffer EE, Wruble LD: Prognostic factors in colorectal carcinomas arising in adenomas: implications for lesions removed by endoscopic polypectomy. Gastroenterology 1985;89:328-336.

-46 Kikuchi R, Takano M, Takagi K, Fujimoto N, Nozaki R, Fujiyoshi T, Uchida Y: Management of early invasive colorectal cancer: risk of recurrence and clinical guidelines. Dis Colon Rectum 1995;38:1286-1295.

47 Tamura S, Onishi S: Laterally spreading colon cancer. N Engl J Med 2004;351:e24.

-48 Rashid A, Zahurak M, Goodman SN, Hamilton SR: Genetic epidemiology of mutated K-ras protooncogene, altered suppressor genes, and microsatellite instability in colorectal adenomas. Gut 1999;44:826-833.

-49 Yao T, Kajiwara M, Kouzuki T, Iwashita A, Tsuneyoshi M: Villous tumor of the colon and rectum with special reference to roles of p53 and Bcl-2 in adenoma-carcinoma sequence. Pathol Int 1999;49:374-382.

50 Arai T, Kino I: Role of apoptosis in modulation of the growth of human colorectal tubular and villous adenomas. J Pathol 1995;176: 37-44. 